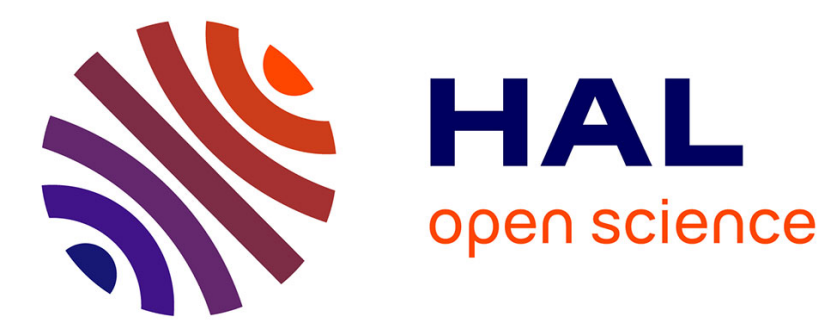

\title{
Structural, morphological and mechanical characteristics of polyethylene, poly(lactic acid) and poly(ethylene-co-glycidyl methacrylate) blends
}

\author{
S. Djellali, N. Haddaoui, T. Sadoun, A. Bergeret, Yves Grohens
}

\section{- To cite this version:}

S. Djellali, N. Haddaoui, T. Sadoun, A. Bergeret, Yves Grohens. Structural, morphological and mechanical characteristics of polyethylene, poly(lactic acid) and poly(ethylene-co-glycidyl methacrylate) blends. Iranian Polymer Journal, 2013, 22 (4), pp.245-257. 10.1007/s13726-013-0126-6 . hal00985412

\section{HAL Id: hal-00985412 \\ https://hal.science/hal-00985412}

Submitted on 10 Jun 2021

HAL is a multi-disciplinary open access archive for the deposit and dissemination of scientific research documents, whether they are published or not. The documents may come from teaching and research institutions in France or abroad, or from public or private research centers.
L'archive ouverte pluridisciplinaire HAL, est destinée au dépôt et à la diffusion de documents scientifiques de niveau recherche, publiés ou non, émanant des établissements d'enseignement et de recherche français ou étrangers, des laboratoires publics ou privés. 


\title{
Structural, morphological and mechanical characteristics of polyethylene, poly(lactic acid) and poly(ethylene-co-glycidyl methacrylate) blends
}

\author{
Souad Djellali • Nacereddine Haddaoui • \\ Tahar Sadoun · Anne Bergeret • Yves Grohens
}

\begin{abstract}
In this work, uncompatibilized and compatibilized blends of low density polyethylene (LDPE) and poly(lactic acid) (PLA) were subjected to several investigations: Fourier transform infrared (FTIR) spectroscopy, morphological analysis and mechanical testing (tensile, impact, microhardness). The copolymer (ethylene-coglycidyl methacrylate) (EGMA) was used as compatibilizer. The percentages of PLA in LDPE/PLA samples ranged from 0 to $100 \mathrm{wt} \%$ while the EGMA was added to the blend 60/40 (LDPE/PLA) at concentrations of 2, 5, 7, 10, 15 and 20 parts per hundred (phr). FTIR analysis showed the absence of any interaction between LDPE and PLA, but after addition of compatibilizer, reactions between epoxy groups of EGMA and carboxylic or hydroxyl groups of PLA were confirmed. Tensile and impact tests revealed a loss of ductility of LDPE with the incorporation of PLA, except for the composition 80/20 (LDPE/PLA). However, the addition of $15 \mathrm{phr}$ of EGMA led to the maximum increase in the elongation-at-break
\end{abstract}

S. Djellali $(\bowtie) \cdot$ N. Haddaoui

Laboratoire de Physico-Chimie des Hauts Polymères (LPCHP),

Département Génie des Procédés, Université Ferhat Abbes, 19000 Sétif, Algéria

e-mail: djellali.souad@yahoo.fr

T. Sadoun

Laboratoire des Matériaux Organiques (LMO), Département

Génie des Procédés, Université A. Mira, 06000 Bejaia, Algéria

\author{
A. Bergeret \\ Centre des Matériaux de Grande Diffusion (CMGD), \\ Ecole des Mine, 30319 Ales, France \\ Y. Grohens \\ Laboratoire Polymères, Propriétés aux Interfaces \\ et Composites (L2PIC), Université de Bretagne Sud, \\ 56321 Lorient Cedex, France
}

(about three times the value of uncompatibilized blend) and in the impact strength, but a marginal improvement was observed for tensile strength. SEM micrographs confirmed that the enhancement of mechanical properties is due to the improvement of the interfacial adhesion between different phases owing to the presence of EGMA. The microhardness values of the different blends (uncompatibilized or compatibilized) were in good agreement with the macroscopic mechanical properties (tensile and impact strengths).

Keywords LDPE - PLA - Compatibilization - EGMA · Microhardness · FTIR

\section{Introduction}

Large amounts of synthetic polymeric materials are produced and used in various field of human activity. When finally discarded, they enter the environment as a noxious waste because of their high resistance to microbiological degradation [1]. Due to its good physical properties in the solid state, its chemical inertness and its low cost, low density polyethylene (LDPE) is one of the most widely used thermoplastics with a current global production of ca. 140 million tons per year [2,3], which results in a large tonnage of waste. Although efforts to recycle used plastics in order to reduce their volume in landfills have been significantly improved, recycling would be neither practical nor economical for certain applications such as waste bags, agricultural mulch films or food packaging $[4,5]$. Hence, to reduce the dependence on landfill, there has been an increased interest in the production of biodegradable polymers [6] by their synthesis or by incorporation of natural polymers into synthetic polymers to enhance their potential 
biodegradability [7]. Polymer blending is in general an effective way of achieving a desirable combination of properties, which are often absent in single component polymers [8]. In the approach of the use of synthetic polymer/natural polymer blends, the biodegradable component, present in sufficient amounts, can be removed by microorganisms in the waste disposal environment and the resulting holes are occupied by either microbes or water leading to extensive degradation of the blend. Consequently, the used plastic or film containing the remaining inert components should disintegrate and disappear [9].

Current commercial biodegradable polymers are mainly aliphatic polyesters, polyethers, poly(vinyl alcohol) and polysaccharides (e.g., starch) [10]. Starch-based blends were first introduced in early 1970s by Griffin [11] who used this natural product as filler in polyethylene in order to increase the biodegradability of the material produced. For the last decades, many papers were focused on such blends [12-14].

Another good example of a biodegradable polymer is poly(lactic acid) (PLA). This aliphatic polyester is derived from renewable agriculture products with properties comparable to that of petrochemical plastics [15]. It is used in different fields from pharmaceutical and medical device to industrial packaging [16] and can degrade to carbon dioxide, water and methane in the environment over a period of several months to 2 years [17].

Poly(lactic acid) is rigid and brittle, thus, it is desirable to improve its mechanical properties, particularly for engineering purposes. This problem can be overcome by blending PLA with other polymers such as PE, which is frequently used as an impact modifier for a variety of other thermoplastics $[18,19]$. Several studies on polylactide and polyethylene blends have been reported. Some authors [20-22] studied the toughening resulting from the incorporation of small amount of PE in PLA or vice versa while others $[23,24]$ attempt to compatibilize this blend using a PE- $b$-PLA block copolymer to enhance interfacial adhesion since PLA and PE are immiscible.

In the present work, this couple of polymers was selected because of their dual advantages: (a) the addition of LDPE could lead to some improvements of mechanical properties of PLA, and (b) the PLA could in turn enhance the biodegradability of LDPE in the blend when being exposed to environmental conditions. Another specificity of this work is the exploitation of the co-continuous structure of blends, which exhibits interesting properties. A survey of the literature indicates extensive work in the area of co-continuous morphologies in polymer blends [25-29].

This paper is focused on the investigation of structural, morphological and mechanical properties of LDPE/PLA blends. The copolymer ethylene-co-glycidyl methacrylate (EGMA) was used as compatibilizer in the 60/40 (LDPE/ PLA) sample, which had a co-continuous structure. This compatibilizer was used by Oyama [30] to enhance 0the toughness of the PLA and the author found that the impact strength of the PLA was improved up to 50 times. In other studies, EGMA was found to be capable to compatibilize blends of polylactide/polycarbonate [31], polyethylene/ polyamide [32] and polyethylene/poly(ethylene terephthalate) [33].

The mechanical properties were measured by means of the tensile, Charpy impact and microhardness testing while structural characteristics were defined using attenuated total reflection Fourier transform infrared (ATR-FTIR) spectroscopy. Morphological observations were performed by SEM technique.

\section{Experimental}

\section{Materials}

Low density polyethylene (LDPE 1003/FE/23) was obtained from Total Petrochemicals, Belgium. The poly (L-lactic acid), PLLA L9000, was purchased from Biomer (Germany). It contains $92 \%$ of L-lactide and $8 \%$ of D-lactide and has a molecular weight of $220,000 \mathrm{~g} / \mathrm{mol}$. The compatibilizer used in this work was a copolymer of ethylene and glycidyl methacrylate (EGMA) (Lotader) produced by Arkema group, France. The most important characteristics of the homopolymers are given in Table 1.

Melt blending and preparation of test specimens

The studied blends containing polyethylene and poly(lactic acid) were prepared from the components in the entire composition range from 0 to $100 \mathrm{wt} \%$. The copolymer EGMA, used as compatibilizer, was added to the blend 60/40 LDPE/PLA at different concentrations $(2,5,7,10$, 15 and $20 \mathrm{phr}$ ). The melt blending for all formulations
Table 1 Characteristics of used polymers

\begin{tabular}{lllllll}
\hline Sample & $\begin{array}{l}\text { Density } \\
\left(\mathrm{g} / \mathrm{cm}^{3}\right)\end{array}$ & $\begin{array}{l}\text { Melt index } \\
(\mathrm{g} / 10 \mathrm{~min})\end{array}$ & $\begin{array}{l}\text { Melting } \\
\text { temperature } \\
\left({ }^{\circ} \mathrm{C}\right)\end{array}$ & $\begin{array}{l}\text { Vicat } \\
\text { temperature } \\
\left({ }^{\circ} \mathrm{C}\right)\end{array}$ & $\begin{array}{l}\text { Tensile } \\
\text { strength } \\
(\mathrm{MPa})\end{array}$ & $\begin{array}{l}\text { Elongation-at- } \\
\text { break }(\%)\end{array}$ \\
\hline LDPE & 0.92 & 0.3 & 111 & 99 & 12 & 350 \\
PLA & 1.25 & $3-6$ & $168-172$ & 56 & 70 & 2.4 \\
\hline
\end{tabular}


were carried out with a twin-screw extruder (Brabender, Germany) having the following profile of temperature: 180-185 ${ }^{\circ} \mathrm{C}$. Before being extruded, all polymers were dried under vacuum at $80{ }^{\circ} \mathrm{C}$ for $24 \mathrm{~h}$ to remove any volatile components. The obtained extrudates were pelletized then compression moulded using a laboratory press into 1 - and 4-mm thick plates at $180{ }^{\circ} \mathrm{C}$ then cooled to room temperature. All measurements were carried out on samples taken from these plates.

\section{FTIR spectroscopy}

The chemical structure of the blends was investigated by ATR-FTIR spectroscopy using a Bruker spectrometer IFS66 (Golden Gate) (Bruker Optics, Germany). Each spectrum was obtained after 64 consecutive scans with a resolution of $4 \mathrm{~cm}^{-1}$, within the range $400-4,000 \mathrm{~cm}^{-1}$.

Blends morphology

An FEI 200-FAG (QUANTA) electron microscope (SEM) (FEI Co., USA) was used to observe the morphology of LDPE/PLA blends, with and without compatibilizer, at an accelerating voltage of $50 \mathrm{kV}$. The specimens were frozen in liquid nitrogen and snapped immediately. The cross sections of the specimens were then coated with a thin layer of carbon in an automatic sputter coater to avoid charging under the electron beam and to increase contrast during observation.

\section{Particle size distribution and polydispersity}

Particle sizes were determined using SEM micrographs of the cryofractured surfaces of blends containing $20 \%$ PLA and $80 \%$ PLA. The software Image tools (IT3) was used to measure particle size of the dispersed phase (500-600 particles). The mean particle size can be calculated based on number $\left(D_{\mathrm{n}}\right)$, weight $\left(D_{\mathrm{w}}\right)$, surface $\left(D_{\mathrm{s}}\right)$ or volume $\left(D_{\mathrm{v}}\right)$, as represented in the following equations [34, 35]:

$D_{\mathrm{n}}=\frac{\sum_{i=1}^{N} n_{i} D_{i}}{\sum_{i=1}^{N} n_{i}}$

$D_{\mathrm{w}}=\frac{\sum_{i=1}^{N} n_{i} D_{i}^{2}}{\sum_{i=1}^{N} n_{i} D_{i}}$

$D_{\mathrm{s}}=\frac{\sum_{i=1}^{N} n_{i} D_{i}^{3}}{\sum_{i=1}^{N} n_{i} D_{i}^{2}}$

$D_{\mathrm{v}}=\frac{\sum_{i=1}^{N} n_{i} D_{i}^{4}}{\sum_{i=1}^{N} n_{i} D_{i}^{3}}$

The distribution parameter (Eq. 5), $\sigma$, accounts for the heterogeneity in the particle sizes or the uniformity in the particle sizes for a particular blend composition. In case of monodispersity, $\sigma=1$ and for polydispersity $\sigma>1$.

$\ln \sigma=\sqrt{\frac{\sum_{i=1}^{N} n_{i}\left(\ln d_{i}-\ln d\right)}{\sum_{i=1}^{N} n_{i}}}$

where $d$, the average diameter of the dispersed phase, is given by:

$\ln d=\frac{\sum_{i=1}^{N} n_{i} \ln d_{i}}{\sum_{i=1}^{N} n_{i}}$

Mechanical measurements

\section{Tensile tests}

Tensile properties were measured at room temperature using a MTS Synergie RT1000 testing apparatus (MTS Systems Co., USA) at a cross-head speed of $1 \mathrm{~mm} / \mathrm{min}$. Dog-bone-shaped tensile specimens were cut from 1-mm thick plates. The specimen shape, dimensions (Type VA) and the cross-head speed were obtained from the norm International Standards Organisation (ISO) 527-2. Young's modulus $(E)$ as well as properties at failure, i.e., tensile strength and elongation-at-break $\left(\sigma_{r}, \varepsilon_{r}\right)$ were obtained from the recorded force versus elongation curves. At least six measurements were conducted for each sample, and the results were averaged to obtain a mean value.

\section{Impact tests}

Charpy impact tests on non-notched rectangular test bars $(60 \times 10 \times 4 \mathrm{~mm})$ were carried out using S-102 Zwick impact tester (Zwick Testing Machines Ltd, Germany) according to ISO 179-1993 test procedure. The impact machine is equipped with a pendulum hammer of $4 \mathrm{~J}$ and a gauge of $40 \mathrm{~mm}$ length. Ten samples were tested for each composition and the average value was reported. All the tests were performed at ambient temperature.

The Charpy impact strength $\left(\mathrm{a}_{\mathrm{cU}}\right)$, expressed in kilojoules per square metre was calculated using the following equation:

$\mathrm{a}_{\mathrm{cU}}=\frac{W}{h * b} 10^{3}$.

where,

$W(\mathrm{~J})$ : energy absorbed by the sample at the fracture;

$h$ (mm): sample thickness;

$b$ (mm): sample width.

\section{Vickers microhardness test}

The microhardness of uncompatibilized and compatibilized LDPE/PLA blends was measured using a Vickers 
microhardness tester (Wilson Hardness, Germany). This test uses a square-shaped diamond pyramid indenter with top angle of $136^{\circ}$. The microhardness, $\mathrm{HV}$, was calculated from the residual projected diagonal impression by applying the following equation [35]:

$\mathrm{HV}=1.854 \frac{P}{d^{2}}$

where $P$ is the force in Newton and $d$ is the mean diagonal length of the impression in millimetres, measured with an optical microscope. The value of $\mathrm{HV}$ is expressed in megapascals. For each formulation ten imprints were made at randomly chosen places of the sample, under an indentation load of $980.7 \mathrm{mN}$ during $10 \mathrm{~s}$.

\section{Results and discussion}

LDPE/PLA blends without compatibilizer

\section{Fourier transform infrared (FTIR)}

The FTIR spectra of LDPE, PLA and their blends are shown in Fig. 1. Four sharp peaks dominate the spectrum of the neat LDPE (Fig. 1 spectrum a): at 2,915, 2,850, 1,465 and $719 \mathrm{~cm}^{-1}$, which are attributed to the stretching and bending vibration of the methylene groups $\left(-\mathrm{CH}_{2}-\right)$. The characteristic absorption band of methyl groups at $1,373 \mathrm{~cm}^{-1}\left(-\mathrm{CH}_{3}\right.$ bending) is also observed in

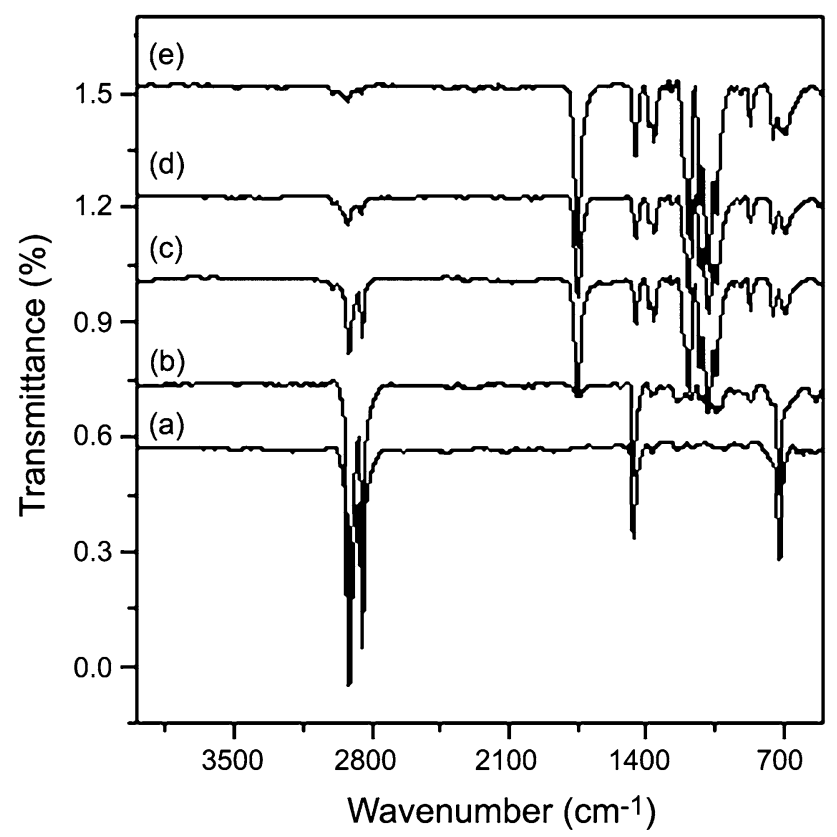

Fig. 1 FTIR spectra of LDPE, PLA and their blends: a LDPE, b 80/ 20, c 50/50, d 20/80 and e PLA this spectrum [36]. The spectrum of the neat PLA (Fig. 1 spectrum e) displays several characteristic peaks; the stretching, deformation and bending vibrations of the $\mathrm{CH}$ appear at 2,997-2,877, 1,456, 1,382-1,300 and $1,130 \mathrm{~cm}^{-1}$. At 953 and $920 \mathrm{~cm}^{-1}$, one can find the bands characteristic of the backbone vibrations $(\mathrm{C}-\mathrm{C})$ with the $\mathrm{CH}_{3}$ rocking modes. The $\mathrm{C}=\mathrm{O}$ stretching region appears at $1,750 \mathrm{~cm}^{-1}$ while the $\mathrm{C}-\mathrm{O}$ stretching mode of the ester group appear at $1,225 \mathrm{~cm}^{-1}$ and the $\mathrm{C}-\mathrm{O}-\mathrm{C}$ asymmetric mode appears at $1,082 \mathrm{~cm}^{-1}$. At 871 and $756 \mathrm{~cm}^{-1}$, appear two bands that can be attributed, respectively, to the amorphous and crystalline phases of PLA [37, 38].

The spectra of the LDPE/PLA blends (Fig. 1 spectra of b-d) display the characteristic bands of the two homopolymers (LDPE and PLA) without any noticeable changes, which indicate the absence of any interaction between them.

\section{Morphology}

Figure 2 illustrates the scanning electron microscope images of cryogenically fractured surfaces of LDPE/PLA blends taken in the entire composition range. From micrographs in Fig. 2a (20 wt $\%$ of PLA) and Fig. 2e ( $20 \mathrm{wt} \%$ of LDPE), it can be seen that the minor phase exhibits a morphology of spherical domains dispersed into the major phase (matrix). Moreover, no interactions between phases are observed and the surfaces left by particles pulled from the matrix are smooth without any visible roughness. The surface roughness of particles is usually expected in case of good interfacial adhesion between the particles and the matrix [39].

The micrographs for the 60/40, 50/50 and 40/60 LDPE/ PLA blends in Fig. 2b-d reveal co-continuous morphologies. Such morphologies consist of only two large polymer domains, one of LDPE and one of PLA, both extending completely throughout the structure. This co-continuous morphology is often characterized by domain branching and domain boundaries that frequently change curvature [40].

However, an interesting phenomenon is observed in the co-continuous structure previously mentioned: there are still LDPE domains in the continuous phase of PLA and vice versa, namely sub-inclusions inside every continuous phase or phase-in-phase structure. The formation of sub-inclusions morphology can be explained by the fact that at phase inversion, a small amount of each phase is enclosed by the newly grown continuous phase [41].

It is also observed that with increasing PLA content, the spherical domains have the tendency to change into spaghetti-like rods. 

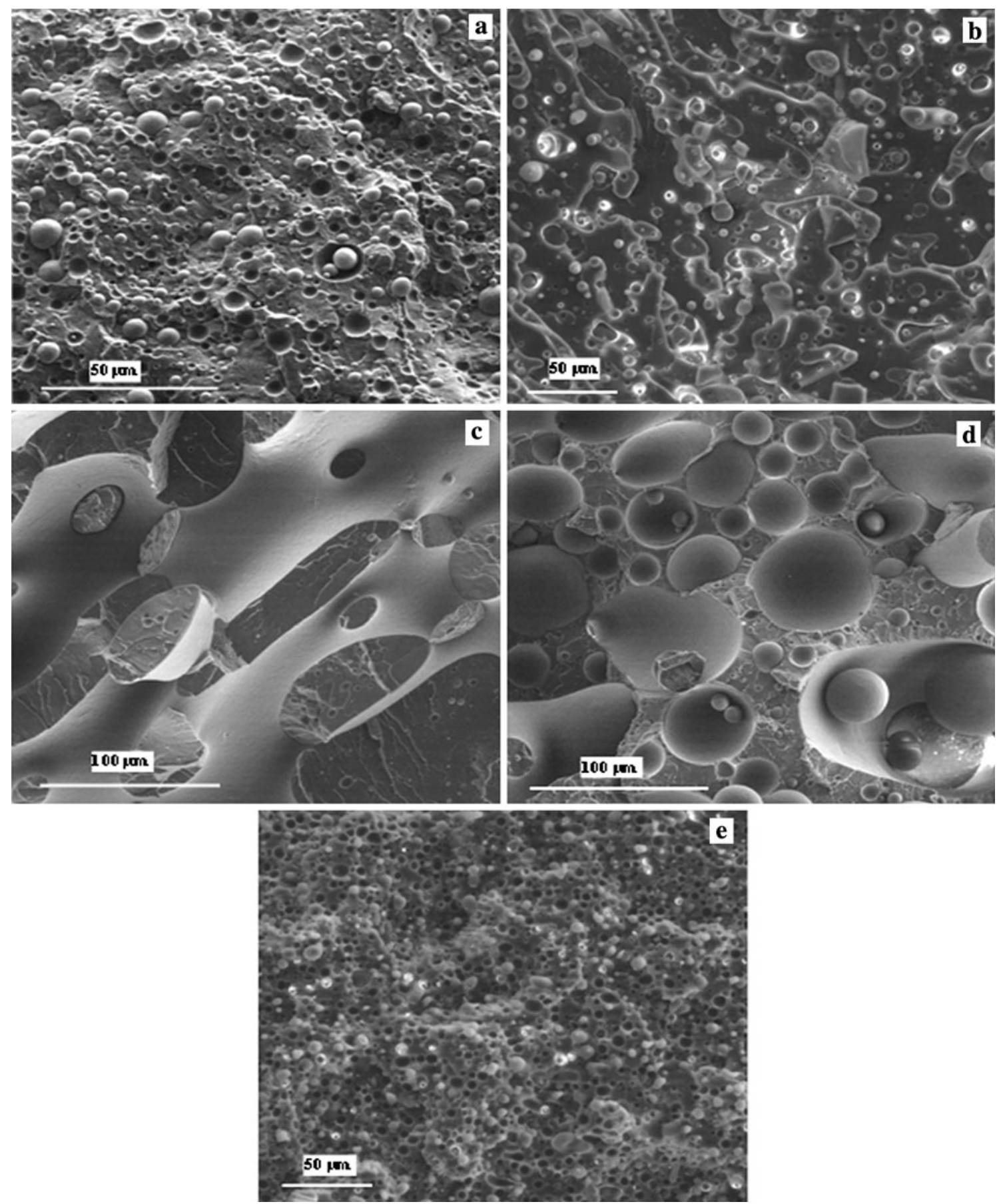

Fig. 2 SEM micrographs of uncompatibilized LDPE/PLA blends: a 80/20 $(\times 2,000)$, b 60/40 $(\times 1,000)$, c 50/50 $(\times 1,000)$, d 40/60 $(\times 1,000)$ and e $20 / 80(\times 1,000)$

\section{Particle size distribution and polydispersity}

Particle size distributions of LDPE/PLA blends, which have the morphology of well-dispersed particles are given in Fig. 3. In Fig. 3a, corresponding to the blend $80 / 20$ (LDPE/PLA), it can be seen that the distribution is narrow and almost all particles are smaller than $9 \mu \mathrm{m}$. However, when the PLA is the continuous phase (Fig. 3b), the particle size distribution is wide with some particles larger than $15 \mu \mathrm{m}$.

The morphological parameters for these two formulations (mean particle size, $D_{n}, D_{w}, D_{s}, D_{v}$, average diameter and distribution parameter) are summarized in Table 2.

For the blend with LDPE matrix (80/20), the average diameter of PLA-dispersed particles is about $3.572 \mu \mathrm{m}$ (Fig. 3a), while blend with PLA matrix (20/80) displays 

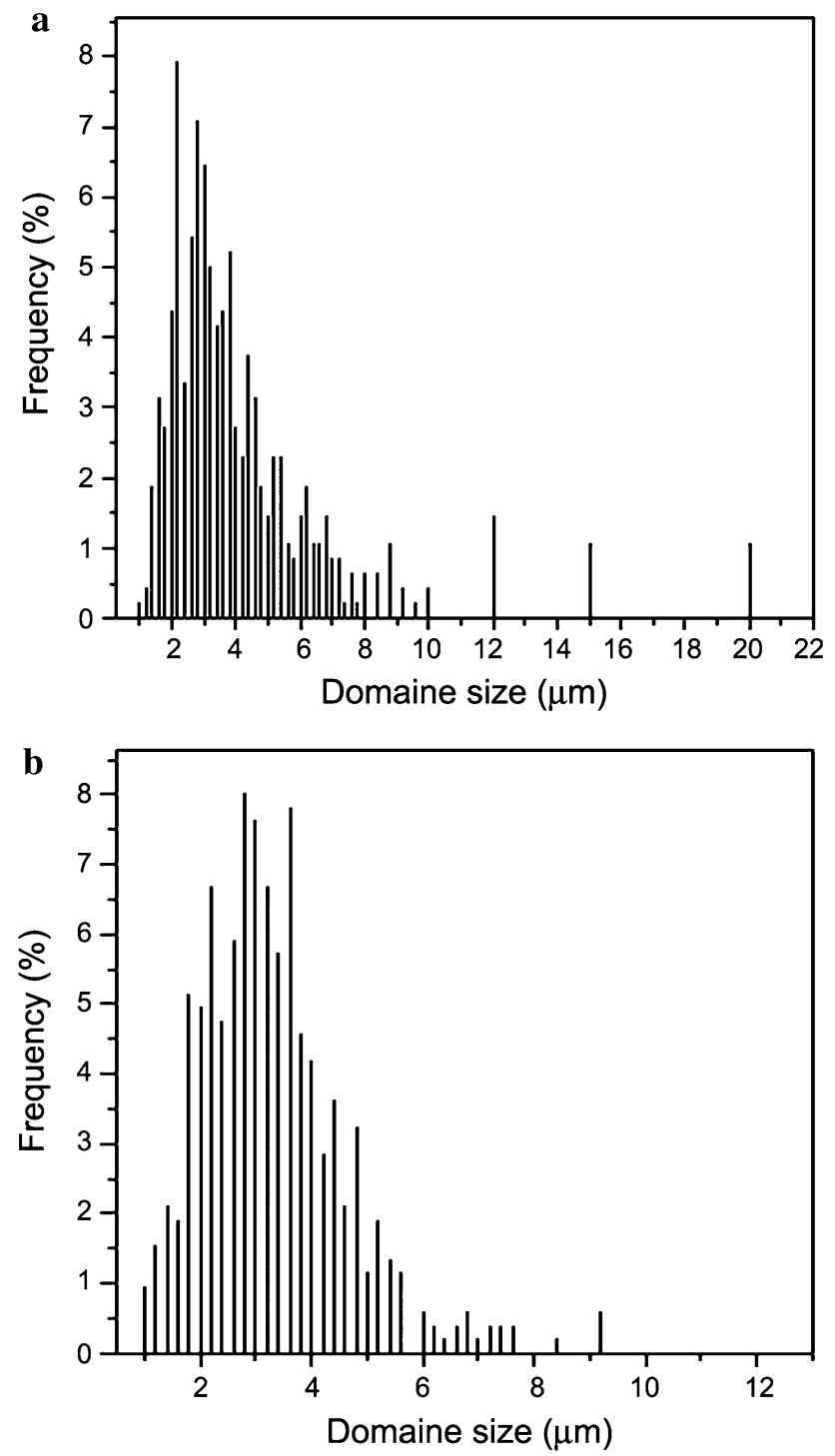

Fig. 3 Particle size distributions of LDPE/PLA blends: a 80/20 and b $20 / 80$

Table 2 Morphological parameters for LDPE/PLA blends with the morphology of well-dispersed particles

\begin{tabular}{lcl}
\hline Morphological parameters & \multicolumn{2}{c}{ LDPE/PLA blends (wt $)$} \\
\cline { 2 - 3 } & $80 / 20$ & $20 / 80$ \\
\hline$D_{\mathrm{n}}$ & 4.14 & 3.3 \\
$D_{\mathrm{w}}$ & 5.973 & 3.824 \\
$D_{\mathrm{s}}$ & 9.158 & 4.42 \\
$D_{\mathrm{v}}$ & 13.029 & 5.095 \\
$d$ & 3.572 & 3.059 \\
$\sigma$ & 1.669 & 1.482 \\
\hline
\end{tabular}

slightly smaller particle size of dispersed LDPE phase with an average diameter of about $3.059 \mu \mathrm{m}$. Similarly, the values of the rest of morphological parameters are greater

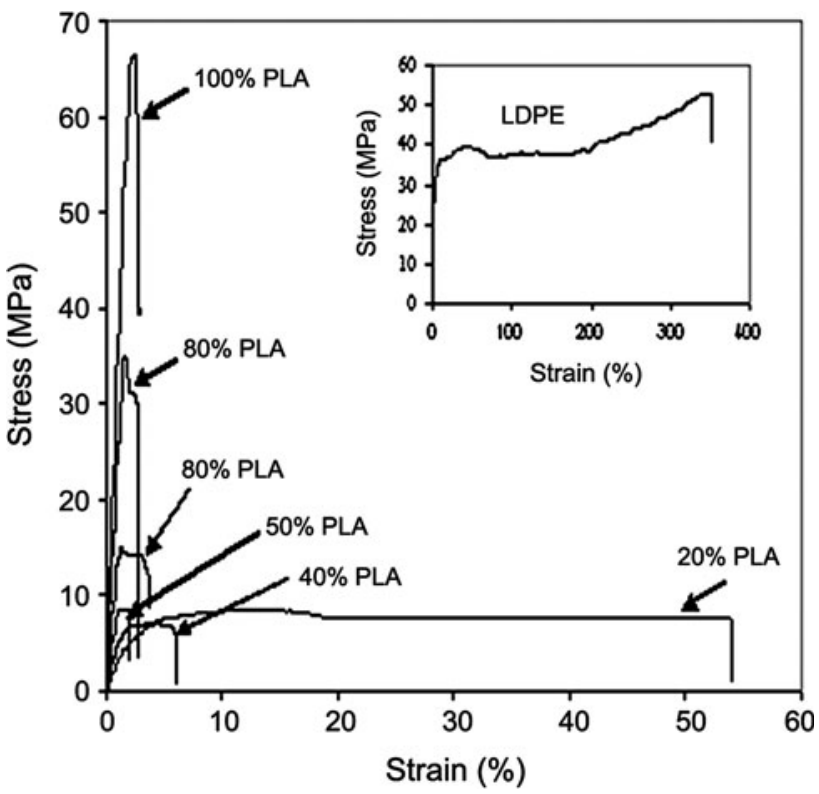

Fig. 4 Stress-strain curves for LDPE, PLA and their blends without compatibilizer

for the blend 80/20 (LDPE/PLA) compared with those of the blend 20/80 (LDPE/PLA). These results show a better dispersion and homogeneity of LDPE particles than PLA particles in their corresponding blends.

Mechanical properties

\section{Tensile properties}

The low-speed stress-strain dependence for LDPE/PLA blends is shown in Fig. 4. The average values and estimated standard deviations of elongation-at-break, tensile strength and elasticity modulus for LDPE, PLA, and their blends are presented in Table 3. These data well illustrate the changes induced by incorporation of the ductile particles of LDPE into PLA.

From Fig. 4, it is observed that while LDPE exhibited a typical ductile behaviour with an elastic modulus of

Table 3 Tensile properties of LDPE, PLA, and their blends

\begin{tabular}{ccccc}
\hline $\begin{array}{l}\text { PLA } \\
(\mathrm{wt} \%)\end{array}$ & $\begin{array}{l}\text { Tensile } \\
\text { strength } \\
\text { (Mpa) }\end{array}$ & $\begin{array}{l}\text { Elasticity } \\
\text { modulus } \\
\text { (Mpa) }\end{array}$ & $\begin{array}{l}\text { Tensile stress- } \\
\text { at-break } \\
\text { (MPa) }\end{array}$ & $\begin{array}{l}\text { Elongation- } \\
\text { at-break (\%) }\end{array}$ \\
\hline 0 & $11.9 \pm 1$ & $269.9 \pm 21.5$ & $11.9 \pm 1.0$ & $302.7 \pm 20$ \\
20 & $8.6 \pm 0.3$ & $349.0 \pm 16.3$ & $8.0 \pm 0.2$ & $48.6 \pm 1.45$ \\
40 & $7.4 \pm 0.3$ & $604.6 \pm 27.3$ & $6.9 \pm 0.3$ & $5.4 \pm 0.9$ \\
50 & $9.5 \pm 0.6$ & $958.9 \pm 17.7$ & $9.3 \pm 0.6$ & $1.2 \pm 0.13$ \\
60 & $15.8 \pm 0.7$ & $1514.0 \pm 36.4$ & $14.7 \pm 0.6$ & $3.1 \pm 0.5$ \\
80 & $34.6 \pm 1.3$ & $2542.2 \pm 85.5$ & $30.7 \pm 2.9$ & $2.4 \pm 0.5$ \\
100 & $64.1 \pm 2.8$ & $3588.2 \pm 85.2$ & $43.4 \pm 5.8$ & $2.8 \pm 0.4$ \\
\hline
\end{tabular}


269.9 MPa and an elongation-at-break of $300 \%$, pure PLA behaved as a rigid and a brittle material with a much higher value for elastic modulus ( $3.59 \mathrm{GPa}$ ) and a very small value for elongation-at-break $(2.8 \%)$. For intermediate formulations, PLA brittle behaviour changes gradually into a pseudo-ductile one with addition of LDPE. A plastic flow appears progressively for the different blends upon toughening mainly for the composition 80/20 LDPE/PLA. In general, the addition of LDPE to PLA reduced the tensile strength and elasticity modulus, but increased slightly the elongation-at-break. The continuous decrease of tensile properties reflects a poor interfacial adhesion. This incompatibility is also revealed by the negative deviation of the values in Table 3 from the linear additivity rule.

The tensile strength of blends exhibited the lowest value of 7.4 MPa for the composition 60/40 (LDPE/PLA), while the elongation-at-break exhibited the lowest value of $1.2 \%$ for the composition 50/50 (LDPE/PLA). However, as the content of LDPE reached $80 \mathrm{wt} \%$, LDPE becomes the continuous phase and the tensile properties increase again.

From the morphological and the mechanical observations, it can be noted that the tensile properties of the blends are strongly dependent on the composition and the morphology. In the case of droplet-matrix morphology, these properties were determined by the properties of the matrix phase. For co-continuous blends, a drastic decrease was observed except for the tensile modulus, which was increased due to the interpenetrating phase structure [42].

\section{Impact properties}

The data of Charpy impact strength obtained for unnotched bars of LDPE/PLA blends are plotted against the blend composition in Fig. 5. It is shown that samples of pure LDPE and LDPE containing $20 \%$ of PLA did not break, indicating that these materials kept their ductile behaviour. However, pure PLA and the other blends exhibited remarkable brittleness with fractures without any prior plastic deformation. The impact resistance values of blends with PLA content greater than $20 \%$ were inferior to that of pure PLA, which is about $14.5 \mathrm{~kJ} / \mathrm{m}^{2}$. The lowest value was observed for the blend $50 / 50\left(5.89 \mathrm{~kJ} / \mathrm{m}^{2}\right)$. These observations confirm the lack of good interfacial adhesion between homopolymers, which is necessary for good stress transfer in the system.

\section{Vickers microhardness}

Like many mechanical properties of solids, microhardness obeys the additivity law [43]:

$H=\Sigma H_{i} w_{i}$

where $H_{\mathrm{i}}$ and $w_{\mathrm{i}}$ are the microhardness and mass fraction, respectively, of each component and/or phase.

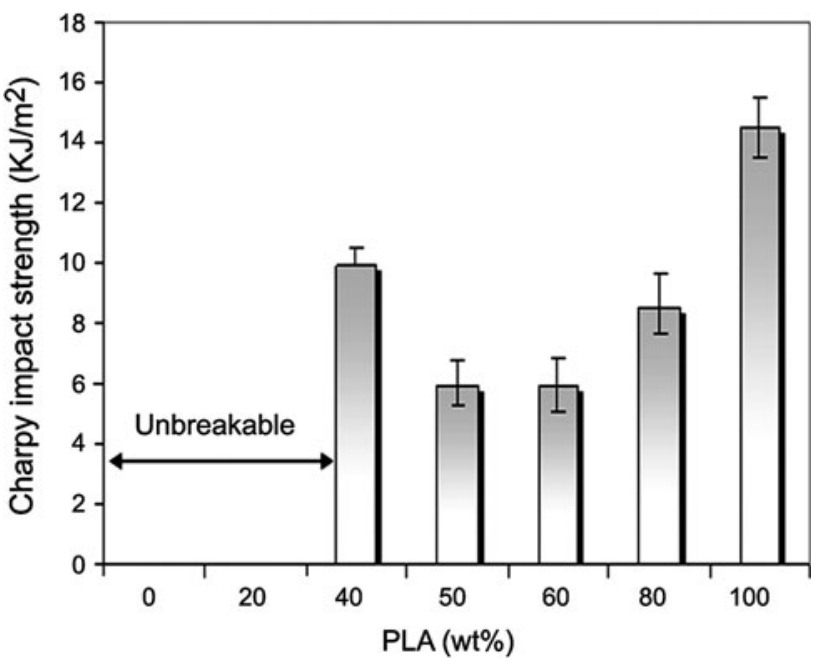

Fig. 5 Effect of PLA content on Charpy impact strength of uncompatibilized LDPE/PLA blends

The microhardness of LDPE phase depends only on the degree of crystallinity since the microhardness of the amorphous phase is $H_{a}^{\mathrm{PE}} \sim 0\left(T_{\mathrm{g}}<0{ }^{\circ} \mathrm{C}\right)$ :

$H^{\mathrm{PE}}=w_{c}^{\mathrm{PE}} H_{c}^{\mathrm{PE}}$

where $H_{c}^{\mathrm{PE}}$ is the hardness value for the crystalline phase. However, for the PLA phase, the hardness of the amorphous phase should be taken into account since measurements are performed at room temperature, i.e., below the glass transition temperature of PLA $\left(\sim 58{ }^{\circ} \mathrm{C}\right)$.

$H^{\mathrm{PLA}}=w_{c}^{\mathrm{PLA}} H_{c}^{\mathrm{PLA}}+w_{a}^{\mathrm{PLA}} H_{a}^{\mathrm{PLA}}$

The experimental hardness values obtained for the neat polymers and their blends are presented in Fig. 6. The dashed line represents the corresponding additive values. The neat homopolymers have very different values of microhardness: $34 \mathrm{MPa}$ for LDPE (ductile material) and $243 \mathrm{MPa}$ for PLA (rigid material). A small decrease is observed in microhardness with addition of $20 \mathrm{wt} \%$ of PLA, which may be explained by the fact that the presence of LDPE (matrix) may inhibits the crystallization of PLA leading to a decrease in crystallinity which, in turn, causes a reduction in the microhardness [43]. For the rest of the blends, the microhardness increase with the incorporation of the PLA but all values were lower than those expected from the additivity law (dashed line).

\section{LDPE/PLA (60/40) blend with compatibilizer}

The compatibilizer, EGMA, used in this work was chosen on the basis of works of Minkova et al. [44] and Oyama [30]. Minkova et al. [44] studied the blend of LDPE with EGMA 


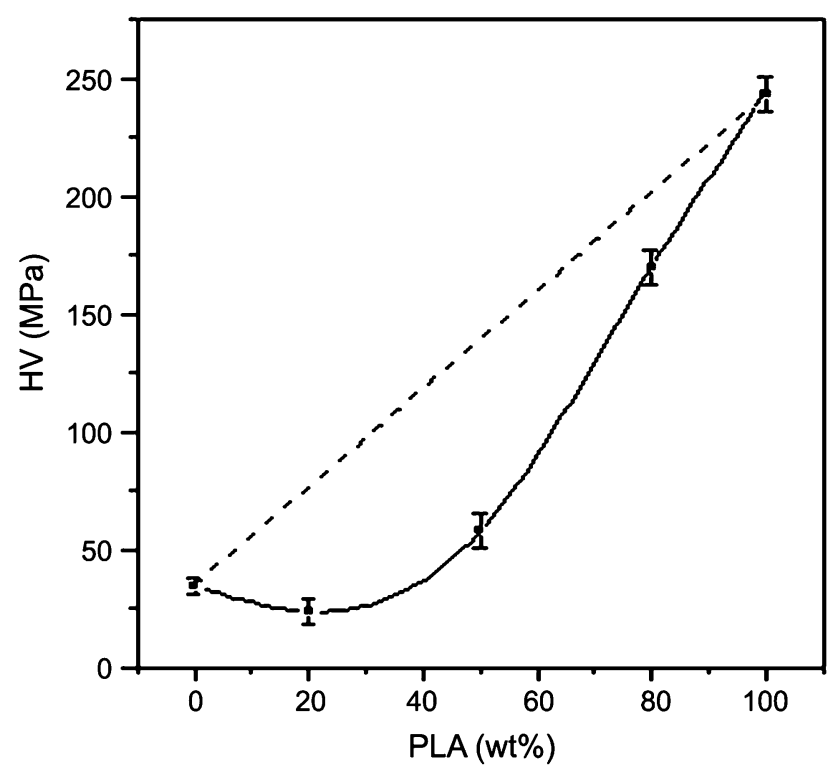

Fig. 6 Vickers microhardness of LDPE/PLA blends as a function of PLA content

and found high compatibility between these two components. On the other hand, the study of Oyama [30] on PLA/ EGMA blends showed an important improvement in the mechanical characteristics of PLA by its reactive blending with EGMA. Thus, an enhancement in the interfacial adhesion in the ternary blend PE/EGMA/PLA could be expected.

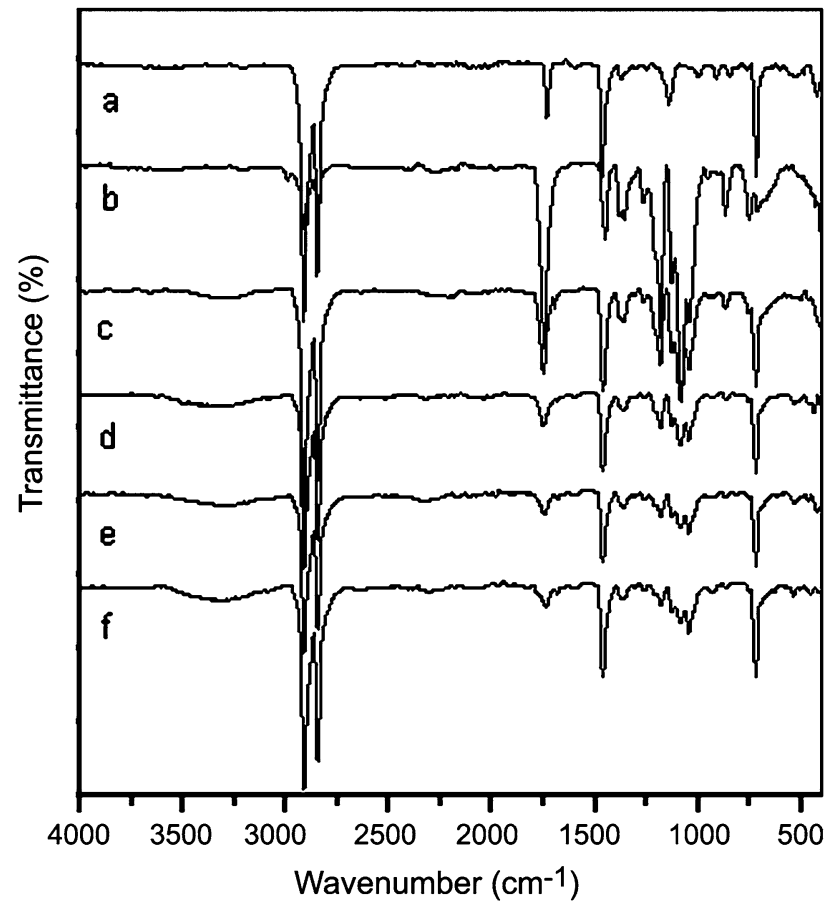

Fig. 7 FTIR spectra of: a EGMA, b uncompatibilized blend, and compatibilized 60/40 LDPE/PLA blends compatibilized at different amounts of compatibilizer: c $5 \mathrm{phr}$, d $10 \mathrm{phr}$, e $15 \mathrm{phr}$ and f $20 \mathrm{phr}$ EGMA
Fig. 8 SEM micrographs of: a uncompatibilized blend and compatibilized 60/40 (LDPE/PLA) blends at different compatibilizer contents: b and b' 2 phr; c and c' 5 phr; d and d' 7 phr; e and e' $10 \mathrm{phr}$; f and f' $15 \mathrm{phr} ; \mathbf{g}$ and g' $20 \mathrm{phr}$ (SEMs (a-g): Magnification $\times 1,000$ and SEMs $(\mathbf{b} '-\mathbf{g}$ '): Magnification $\times 10,000$ )

\section{Fourier transform infrared (FTIR)}

The spectra of 60/40 LDPE/PLA blend compatibilized with different amounts of the copolymer EGMA are shown in Fig. 7. The spectrum of the copolymer ethylene-co-glycidyl methacrylate (Fig. 7, spectrum a) displays the presence of epoxide FTIR bands positioned at 997, 910 and $847 \mathrm{~cm}^{-1}$, the $\mathrm{C}=\mathrm{O}$ band at $1,734 \mathrm{~cm}^{-1}$, as well as the characteristic bands of the polyethylene. The spectra of compatibilized blends (Fig. 7, spectra of c-e) show several changes; the most important and worth mentioning are: (a) the disappearance of the characteristic bands of the compatibilizer $\left(998,910\right.$ and $\left.849 \mathrm{~cm}^{-1}\right)$ (b) the reduction of the carbonyl band $\left(1,734 \mathrm{~cm}^{-1}\right)$ with increase in the amount of the compatibilizer and (c) the appearance of new band in the region of $3,200 \mathrm{~cm}^{-1}$, which can be assigned to bounded hydroxyl groups $(\mathrm{OH})$. All these changes confirm the reaction occurring between the epoxy groups of GMA and the functional groups (hydroxyl and carbonyl) of the PLA, which lead to a good compatibilization of the blend.

Also, as seen in spectra of compatibilized blends, the carbonyl bands shift from 1,747 to $1,730 \mathrm{~cm}^{-1}$, which may be due to hydrogen bonds or cross-linking.

\section{Morphology}

The series of SEM micrographs obtained for the 60/40 (LDPE/PLA) blend with different EGMA contents are presented in Fig. 8. These micrographs illustrate the effect of addition of the compatibilizer on the morphology of the blend 60/40 (LDPE/PLA).

From micrographs in Fig. 8a-g, it can be seen that the shape and apparent size of the phases change continuously. The compatibilizer has the tendency to reduce the co-continuous domains leading to much finer co-continuous structure of the compatibilized blends than that of the uncompatibilized blend. This indicates that the compatibilizer, being localized at the interface, had retarded the coalescence of the dispersed phase. However, this effect is more noticeable for $20 \mathrm{phr}$ of EGMA where more and more droplets are discernible in the matrix. This is in agreement with published reports indicating that compatibilizers play a role similar to emulsifiers in liquid emulsions: they help to stabilize the morphology of immiscible blends and extend the range of droplet-matrix morphology $[25,45,46]$.

Figure 8b'-g' show micrographs of the 60/40 (LDPE/ PLA) blend containing various amounts of EGMA at 

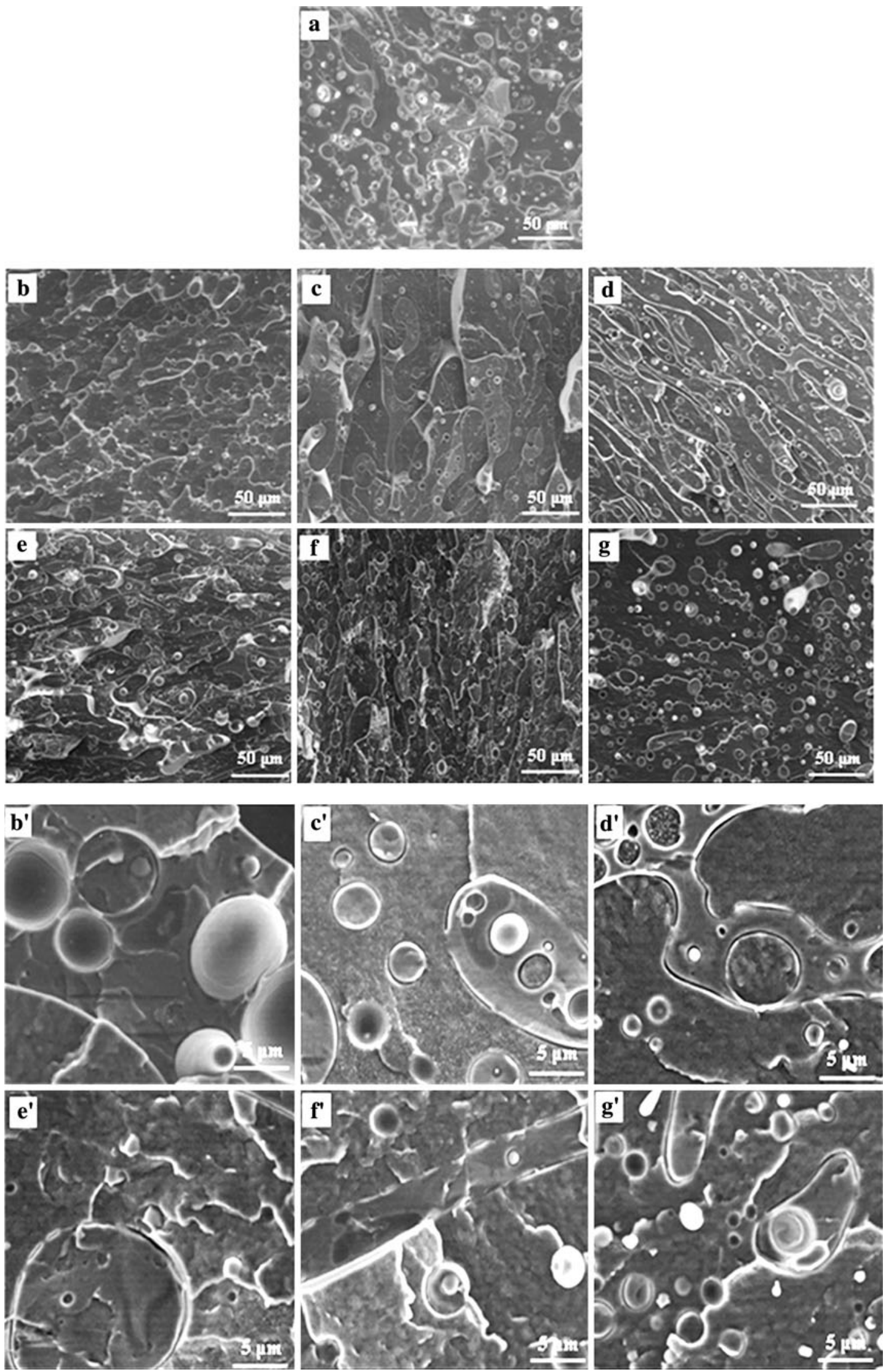
higher magnification. This magnification can help to illustrate the interface between LDPE and PLA domains. It can be observed for small amounts of compatibilizer (2-7 phr) that the interface between the LDPE matrix and the PLA is still smooth and clear, except fewer points of junction, suggesting poor adhesion between the two phases thus poor mechanical properties. When the EGMA content reached $10 \mathrm{phr}$ (Fig. 8e'), the micrograph showed that the copolymer is more concentrated at the interface, therefore the interfacial adhesion between the two phases is improved.

As the level of EGMA attained 15 phr (Fig. 8f'), the interface between the blend phases showed further connections where the component domains are almost indistinguishable. At 20 phr (Fig. 8g'), the compatibilizer had the tendency to be localised inside phases rather than at the interface and the presence of emulsion-in-emulsion morphology is clearly seen, but there are still few connections between the two phases. This is the reason of dropping of mechanical properties at this content as is discussed in the next section.

\section{Mechanical properties}

\section{Tensile properties}

Figure 9 illustrates the stress-strain curves for the 60/40 (LDPE/PLA) blend for various amounts of the compatibilizer EGMA (from 2 to $20 \mathrm{phr}$ ). The average values and calculated standard deviations of the tensile properties (elongation-at-break, tensile strength and elasticity modulus) obtained from these curves are presented in Table 4. It can be observed that when the EGMA content is low

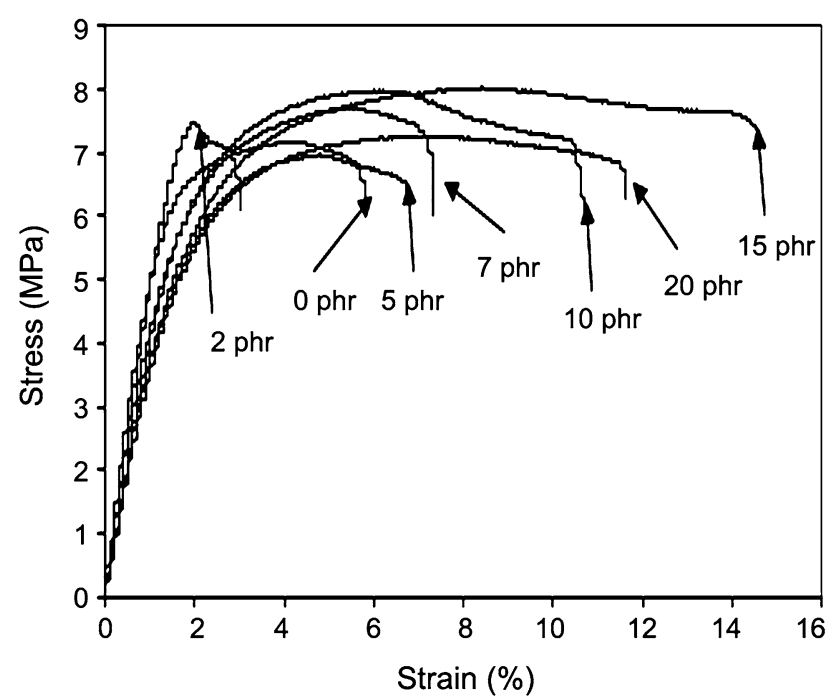

Fig. 9 Stress-strain curves of 60/40 LDPE/PLA blend containing different amounts of compatibilizer
Table 4 Tensile properties of 60/40 LDPE/PLA blend containing the compatibilizer

\begin{tabular}{lllll}
\hline $\begin{array}{l}\text { EGMA } \\
(\mathrm{phr})\end{array}$ & $\begin{array}{l}\text { Tensile } \\
\text { strength } \\
(\mathrm{Mpa})\end{array}$ & $\begin{array}{l}\text { Elasticity } \\
\text { modulus } \\
(\mathrm{Mpa})\end{array}$ & $\begin{array}{l}\text { Tensile stress- } \\
\text { at-break } \\
(\mathrm{MPa})\end{array}$ & $\begin{array}{l}\text { Elongation- } \\
\text { at-break } \\
(\%)\end{array}$ \\
\hline 0 & $7.4 \pm 0.3$ & $604.6 \pm 27.3$ & $6.9 \pm 0.3$ & $5.4 \pm 0.9$ \\
2 & $7.4 \pm 0.4$ & $542.8 \pm 30.8$ & $6.7 \pm 0.2$ & $2.9 \pm 0.5$ \\
5 & $7.5 \pm 0.2$ & $501.3 \pm 32.9$ & $6.8 \pm 0.1$ & $7.1 \pm 0.8$ \\
7 & $7.3 \pm 0.1$ & $426.2 \pm 33.9$ & $6.5 \pm 0.2$ & $7.3 \pm 0.9$ \\
10 & $7.3 \pm 0.2$ & $412.9 \pm 33.9$ & $6.7 \pm 0.2$ & $9.8 \pm 1.0$ \\
15 & $7.9 \pm 0.2$ & $435.1 \pm 37.2$ & $7.1 \pm 0.2$ & $14.7 \pm 0.5$ \\
20 & $7.1 \pm 0.1$ & $374.3 \pm 20.4$ & $6.7 \pm 0.1$ & $11.8 \pm 0.9$ \\
\hline
\end{tabular}

( 2 phr), the blend behaves as a rigid material with an elongation-at-break lower than that of the uncompatibilized blend. However, as the EGMA content increased the blends show an increase in the plastic flow before rupture. The elongation-at-break increases gradually to reach the maximum value $(14.7 \%)$ for $15 \mathrm{phr}$ of compatibilizer, i.e., about three times greater than the value obtained for the uncompatibilized blend. This enhancement may be due to the localization of the copolymer at the interface inducing a decrease in interfacial tension between LDPE and PLA phases and allowing the achievement of good ultimate mechanical properties. But, when EGMA content exceeds $15 \mathrm{phr}$, the elongation-at-break starts to drop till $11.8 \%$, which is an abnormal behaviour. This decrease in elongation-at-break may be attributed to the formation of crosslinked structure resulting from the excessive reaction between the epoxy group of GMA and the many hydroxyl groups arising from the epoxy-carboxyl reaction [30].

The data also show that, while the presence of the compatibilizer did not affect the maximal tensile strength and tensile strength-at-break, the elasticity modulus has gradually decreased with the increase of EGMA content. This result would be expected considering the elastomeric nature of this compatibilizer.

Impact properties

The relationship between the impact strength of 60/40 LDPE/PLA blend and the content of compatibilizer is presented in Fig. 10. The first observation is that, during the test, all samples have a brittle fracture mode without any plastic flow before failure. The impact strength of unnotched samples decreased rapidly when small amount ( $2 \mathrm{phr}$ ) of the compatibilizer was introduced, where it dropped from 9.93 (no compatibilizer) to $6.28 \mathrm{~kJ} / \mathrm{m}^{2}$. A gradual increase in the impact strength was observed for 5 and $7 \mathrm{phr}$ but their values, 7.45 and $7.92 \mathrm{~kJ} / \mathrm{m}^{2}$, respectively, were still lower than that of the uncompatibilized 


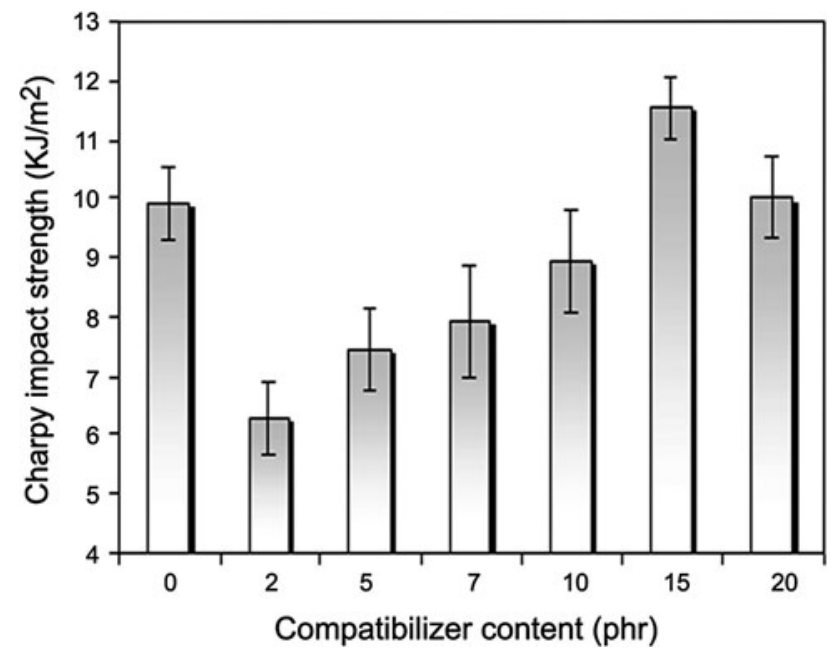

Fig. 10 Effect of the compatibilizer content on Charpy impact strength of 60/40 (LDPE/PLA) blend

blend. However, there was a slight improvement for 10, 15 and $20 \mathrm{phr}$ content of compatibilizer, but the more notable one was for $15 \mathrm{phr}$ where the impact strength of compatibilized blend increased by about 1.2 times.

This suggests that the EGMA has good potential to increase the impact strength of such blends since it lowers the interfacial tension, which ensures the required level of interfacial adhesion between components, thus promoting a better stress transfer in the system. One can improve further this impact strength if the PLA becomes softer by lowering its glass transition temperature with addition of a suitable plasticizer [47-49].

\section{Vickers microhardness}

Figure 11 illustrates the microhardness variation of the ternary blend (LDPE/PLA/EGMA) as a function of EGMA content. At low contents of the compatibilizer (2-5 phr), there is a gradual increase in the microhardness of the blend, which corroborate with results of Minkova et al. [44] and Oyama [30]. According to the results of Minkova [44], the values of microhardness of LDPE/EGMA blends obeyed the additivity law. On the other hand, the results of Oyama [30] showed an increase in the crystallinity of PLA when the rate of EGMA was low, increasing thus the microhardness of the PLA phase.

Beyond $5 \mathrm{phr}$ of compatibilizer, a decrease in the microhardness of the mixture was observed which reflected the good compatibilizing effect of EGMA due to the formation of graft copolymers PLA-EGMA at the interface [30]. The lowest value of microhardness is observed for $15 \mathrm{phr}$ EGMA. However, a second increase in the microhardness was noted for $20 \mathrm{phr}$ of compatibilizer, which may be due to cross-linking caused by the excessive

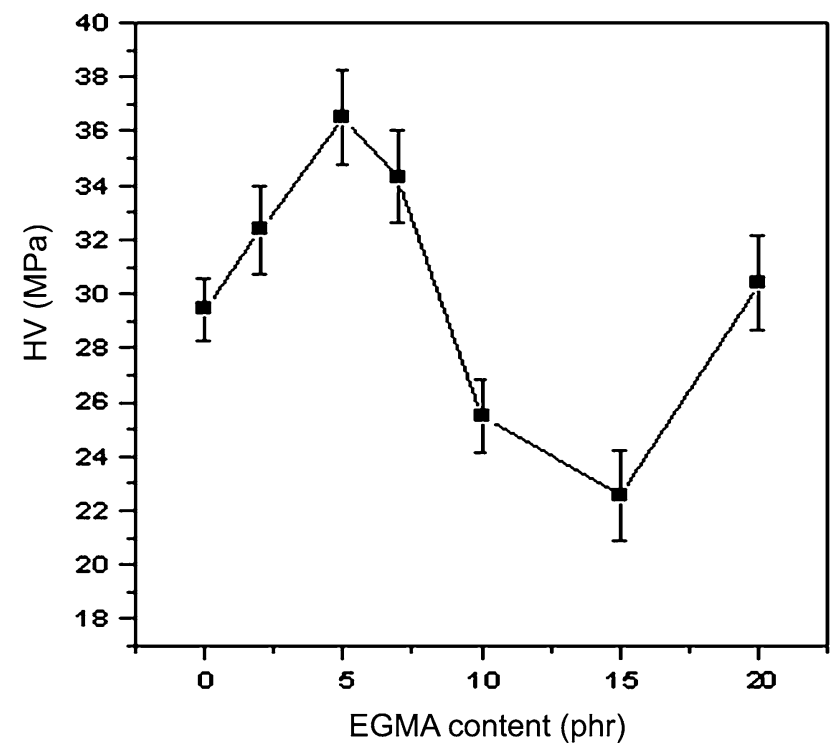

Fig. 11 Vickers microhardness variation of the ternary blends (LDPE/PLA/EGMA) as a function of compatibilizer content

reactions between the epoxy group of EGMA and the acid and hydroxyl groups of PLA, or cross-linking of the compatibilizer itself.

\section{Conclusion}

In this study, structural, morphological and mechanical properties of uncompatibilized LDPE/PLA blends and 60/40 (LDPE/PLA) blend compatibilized with the copolymer (ethylene-co-glycidyl methacrylate) (EGMA) were investigated.

The FTIR results confirmed the reaction occurring between the epoxy groups of GMA and the functional groups (hydroxyl and carbonyl) of the PLA, which led to a good compatibilization of the blend. The morphological study supported the FTIR results and showed that the incorporation of EGMA in the blend LDPE/PLA (60/40) at a level greater than $7 \mathrm{phr}$ led to further connections between the blend phases and the component domains are almost indistinguishable. From the results of mechanical properties (impact and tensile strengths), the uncompatibilized blends show a typical behaviour of immiscible blends with a sharp drop in these properties. However, the 60/40 (LDPE/PLA) blends containing $15 \mathrm{phr}$ of EGMA showed maximum mechanical strengths. The microhardness characteristics of the different blends (uncompatibilized or compatibilized) were in good agreement with the macroscopic mechanical properties such as yield stress, Young modulus, impact strength, etc. Based on the results obtained by the different techniques used in this study, we can conclude that the immiscible LDPE/PLA blends can 
efficiently be compatibilized by the EGMA. The later is able to create chemical bonds between macromolecular chains of the different polymers.

\section{References}

1. Lugauskas A, Prosychevas I, Levinskaité L, Jaskelevičius B (2004) Physical and chemical aspects of long-term biodeterioration of some polymers and composites. Environ Toxicol $19: 318-328$

2. Guerreiro SDC, João IM, Pimentel Real LE (2012) Evaluation of the influence of testing parameters on the melt flow index of thermoplastics. Polym Test 31:1026-1030

3. Sivan A (2011) New perspectives in plastic biodegradation. Curr Opin Biotechnol 22:422-426

4. Nicholson JW (2006) The chemistry of polymers, chapter 11 . The Royal Society of Chemistry, Cambridge

5. Corvaglia P, Passaro A, Manni O, Barone L, Maffezzoli A (2006) Recycling of PP-based sandwich panels with continuous fiber composite skins. J Thermoplast Compos Mater 19:731-745

6. Yin Q, Dong A, Wang J, Yin Y (2008) Rheological and thermal behaviour of starch/LDPE blends containing EAA. Polym Compos 29:745-749

7. Rosa DS, Guedes CGF, Carvalho CLJ (2007) Processing and thermal, mechanical and morphological characterization of postconsumer polyolefins/thermoplastic starch blends. J Mater Sci 42:551-557

8. Chen GX, Kim HS, Kim ES, Yoon JS (2005) Compatibilizationlike effect of reactive organoclay on the poly( $L$-lactide)/ poly(butylene succinate) blends. Polymer 46:11829-11836

9. Chandra R, Rustgi R (1998) Biodegradable polymers. Prog Polym Sci 23:1273-1335

10. Wang L, Ma W, Gross RA, McCarthy SP (1998) Reactive compatibilization of biodegradable blends of poly(lactic acid) and poly( $\varepsilon$-caprolactone). Polym Degrad Stab 59:161-168

11. Griffin GJL (1977) Biodegradable synthetic resin sheet material containing starch and a fatty material. US Patent 4016117

12. Otey EH, Mark AM, Mehltretter CL, Russell CR (1974) Starch based film for degradable agricultural mulch. Ind Eng Chem Prod Res Dev 13:90-92

13. Albertsson AC, Barenstedt C, Karlsson S, Lindberg T (1995) Degradation product pattern and morphology changes as means to differentiate abiotically and biotically aged degradable polyethylene. Polymer 36:3075-3083

14. Djellali S, Benmahmoud N, Sadoun T (2009) Biodegradation of low density polyethylene/starch films exposed to soil burial. Ann Chim Sci Mat 34:41-48

15. Cadar O, Paul M, Roman C, Miclean M, Majdik C (2012) Biodegradation behaviour of poly(lactic acid) and (lactic acidethylene glycol-malonic or succinic acid) copolymers under controlled composting conditions in a laboratory test system. Polym Degrad Stab 97:354-357

16. Iovino R, Zullo R, Rao MA, Cassar L, Gianfreda L (2008) Biodegradation of poly(lactic acid)/starch/coir biocomposites under controlled composting conditions. Polym Degrad Stab 93:147-157

17. Yew GH, Mohd Yusof AM, Mohd Ishak ZA, Ishiaku US (2005) Water absorption and enzymatic degradation of poly(lactic acid)/ rice starch composites. Polym Degrad Stab 90:488-500

18. Zhang JF, Sun X (2005) Poly(lactic acid)-based bioplastics. In: Smith R (ed) Biodegradable polymers for industrial applications, chapter 10. Woodhead, Cambridge
19. Utracki LA (2002) Introduction to polymer blends. In: Utracki LA (ed) Polymer blends handbook, chapter 1. Kluwer, Dordrecht

20. Anderson KS, Lim SH, Hillmyer MA (2003) Toughening of polylactide by melt blending with linear low-density polyethylene. J Appl Polym Sci 89:3757-3768

21. Balakrishnan H, Hassan A, Wahit MU (2010) Mechanical, thermal, and morphological properties of polylactic acid/linear low density polyethylene blends. J Elastom Plast 42:223-239

22. Rezgui F, G'Sell C, Dahoun A, Hiver JM, Sadoun T (2011) Plastic deformation of low-density polyethylene reinforced with biodegradable polylactide, part 1: microstructural analysis and tensile behavior at constant true strain-rate. Polym Eng Sci 51:117-125

23. Wang Y, Hillmyer MA (2001) Polyethylene-poly(L-lactide) diblock copolymers: synthesis and compatibilization of poly $(L-$ lactide)/polyethylene blends. J Polym Sci Part A Polym Chem 39:2755-2766

24. Anderson KS, Hillmyer MA (2004) The influence of block copolymer microstructure on the toughness of compatibilized polylactide/polyethylene blends. Polymer 45:8809-8823

25. Harrats C, Thomas S, Groeninckx G (2006) Micro- and nanostructured multiphase polymer blend systems: phase morphology and interfaces, chapter 3. CRC Press, New York

26. Liu X-Q, Bao R-Y, Liu Z-Y, Yang W, Xie B-H, Yang M-B (2013) Effect of nano-silica on the phase inversion behavior of immiscible PA6/ABS blends. Polym Test 32:141-149

27. Don T-M, Hsu Y-C, Tai H-Y, Fu E, Cheng L-P (2012) Preparation of bi-continuous macroporous polyamide copolymer membranes for cell culture. J Membrane Sci 415-16:784-792

28. Maeji NJ, Rasoul F, Kambouris P, Shao L, Whittaker M (2003) Polymers having co-continuous architecture. US Patent 20030022994 A1

29. Tsai CC, Shih HH, Lai HM (2003) Biodegradable porous devices for tissue engineering. US patent 20030072790 A1

30. Oyama HT (2009) Super-tough poly(lactic acid) materials: reactive blending with ethylene Copolymer. Polymer 50:747-751

31. Lee JB, Lee YK, Choi GD, Na SW, Park TS, Kim WN (2011) Compatibilizing effects for improving mechanical properties of biodegradable poly (lactic acid) and polycarbonate blends. Polym Degrad Stab 96:553-560

32. Yordanov C, Minkova L (2005) Fractionated crystallization of compatibilized LDPE/PA6 blends. Eur Polym J 41:527-534

33. Pluta M, Bartczak Z, Pawlak A, Galeski A, Pracella M (2001) Phase structure and viscoelastic properties of compatibilized blends of PET and HDPE recyclates. J Appl Polym Sci 82:1423-1436

34. Henk GM (2009) Particle size measurements: fundamentals, practice, quality, chapter 2. Springer, New York

35. Balamurugan GP, Maiti SN (2007) Influence of microstructure and deformation behavior on toughening of reactively compatibilized polyamide 6 and poly(ethylene-co-butyl acrylate) blends. Eur Polym J 43:1786-1805

36. Gulmine JV, Janissek PR, Heise HM, Akcelrud L (2002) Polyethylene characterization by FTIR. Polym Test 21:557-563

37. Kister G, Cassanas G, Vert M (1998) Effects of morphology, conformation and configuration on the IR and Raman spectra of various poly(lactic acid)s. Polymer 39:267-273

38. Gonçalves CMB, Coutinho JAP, Marrucho IM (2010) Optical properties. In: Auras R, Lim LT, Selke SEM, Tsuji H (eds) Poly(lactic acid): synthesis, structures, properties, processing, and applications, chapter 8. Wiley, New Jersey

39. Omonov TS, Harrats C, Groeninckx G (2005) Co-continuous and encapsulated three phase morphologies in uncompatibilized and reactively compatibilized polyamide 6/polypropylene/polystyrene ternary blends using two reactive precursors. Polymer 46:12322-12336 
40. Thirtha V, Lehman R, Nosker T (2006) Morphological effects on glass transition behavior in selected immiscible blends of amorphous and semicrystalline polymers. Polymer 47:5392-5401

41. Su R, Su J, Wang K, Yang C, Zhang Q, Fu Q (2009) Shearinduced change of phase morphology and tensile property in injection-molded bars of high-density polyethylene/polyoxymethylene blends. Eur Polym J 45:747-756

42. Willemse RC, Speijer A, Langeraar AE, Posthuma de Boer A (1999) Tensile moduli of co-continuous polymer blends. Polymer 40:6645-6650

43. Balta-Calleja FJ, Fakirov S (2007) Microhardness of polymers, chapter 5. Cambridge university press, New York

44. Minkova L, Hr Yordanov, Filippi S (2002) Characterization of blends of LDPE and PA6 with functionalized polyethylenes. Polymer 43:6195-6204
45. Bourry D, Favis BD (1998) Cocontinuity and phase inversion in HDPE/PS blends: influence of interfacial modification and elasticity. J Polym Sci Part B: Polym Phys Ed 36:1889-1899

46. Yan L-T, Sheng J (2006) Analysis of phase morphology and dynamics of immiscible PP/PA1010 blends and its partial-miscible blends during melt mixing from SEM patterns. Polymer 47:2894-2903

47. Martin O, Averous L (2001) Poly(lactic acid): plasticization and properties of biodegradable multiphase systems. Polymer 42: 6209-6219

48. Burgos N, Martino VP, Jiménez A (2013) Characterization and ageing study of poly(lactic acid) films plasticized with oligomeric lactic acid. Polym Degrad Stab 98:651-658

49. Ljungberg N, Wesslén B (2005) Preparation and properties of plasticized poly(lactic acid) films. Biomacromolecules 6:1789-1796 